\title{
Labelling the axes of graphs . . .
}

The subject of how to express numbers on the axes of graphs-most particularly powers of ten - was the subject of letters from C. Liébecq (Nature 314, 586; 1985 ) and P. Lukyx (Nature 315, 462; 1985). The discussion continues . . .

Sir-Liébecq and Lukyx have identified a source of confusion and occasional error in the numerical tabulation of quantities. The author who wants to express concisely a quantity such as 1.5 million joules in a table has at least three choices for the column heading. They are: Energy $\times 10^{-6}$ $(\mathrm{J})$; Energy $\left(\mathrm{J} \times 10^{6}\right)$ or Energy $(\mathrm{MJ})$. In each case the numerical entry is 1.5. I suggest that the first two possibilities are correct but confusing. The third is to be preferred. A fourth possibility is to use the pure number created by dividing the quantity by its unit (Energy/MJ). Although internationally recommended, this option has been shunned by authors and editors alike.

Finally, may I express the hope that both your contributors were aware of the dual enormity of expressing "radioactivity" in "c.p.m.". Radioactivity is a phenomenon. The quantity is activity and its unit is the reciprocal second, named for this purpose the becquerel. Colloquially the unit may become transition/second, although the entity, transition (not count!), is implicit in the definition of the quantity and should not be duplicated in the unit - compare frequency in $\mathrm{s}^{-1}$, no longer in cycles/second.

H. J. DUNSTER National Radiological Protection Board, Chilton, Didcot, Oxfordshire $O X 110 R Q, U K$

SIR-In recent weeks this column has seen a complaint by Liébecq that a graph axis annotated with figures ranging from 1 to 10 and labelled "Radiactivity (c.p.m. $\times$ $10^{-3}$ )" is incorrectly labelled when one of the implied values is, for example, 5,000 c.p.m.; and a response by Luykx, arguing that the original labelling can be defended as long as one abandons an algebraic interpretation of the symbols. Luykx comments that "there ought to be agreement" on how to read the axis labelling.

It is clear that agreement has not yet been reached, but at least a completely rational system is available, and is particularly well described in the invaluable document Quantities, Units and Symbols, prepared by the Symbols Committee of the Royal Society and representing the recommendations of several international bodies concerned with the proper use of scientific notation.

The example above required the observation that if "Radioactivity $=5 \times$ $10^{3}$ c.p.m." then "5 = Radioactivity/ (c.p.m. $\times 10^{3}$ )". Thus, the right-hand sides of any of these last three equations are acceptable labels for an axis which includes the numerical value 5 , whereas the expressions recommended by both
Liébecq and Luykx are not. Given the evident attraction of such an unambiguous system for labelling graph axes and table columns, it is indeed hard to understand why so many scientists (and all too many of the journals which publish their work) insist on using labelling systems which call for inspired guesswork on the part of the reader.

LIONEL WILSON Department of Environmental Science, University of Lancaster, Lancaster LA1 4YQ, UK

SiR-Luykx concedes that Liébecq would be correct if ordinate labels were thought of as equations in the form "radioactivity $=5,000 \times$ c.p.m.". Luykx also wishes that agreement could be reached about how such labels should be read.

On the first point, the opening, defining, sentence of the Royal Society's report Symbols, Signs and Abbreviations recommended for British Scientific Institutions (1969) contains the equation "physical quantity $=$ numerical value $\times$ unit", that is, exactly in the form that Luykx considers illogical. On the second point, the Royal Society's document represents not only itself but also several leading British scientific societies including the (now) Royal Society of Chemistry and the Institute of Physics, and agrees with all of the major international bodies concerned, including IUPAC, IUPAP, ISO and CGPM. So it is clear that a considerable degree of consensus has existed for many years.

The confusion can be removed by always attaching the power to the physical quantity rather than to the unit; that is, $10^{-3} \times$ radioactivity (c.p.m.) $=5$ means that the radioactivity is 5,000 c.p.m. This journal (the Australian Journal of Plant Physiology) follows that convention as do many others. Of course, the problem can often be avoided by use of SI units and their standard prefixes.

L.W. Martinelli Australian Journal of Plant Physiology, 314 Albert Street,

East Melbourne 3002, Australia

SIR-There have been two letters on the expression of large or small numbers on figure coordinates, the most recent by Luykx. He points out that there ought to be agreement on how to read them.

The Journal of Bacteriology, as with other American Society for Microbiology publications, follows the convention of expressing a large number such as, for example, $10^{9}$ cells $/ \mathrm{ml}$, as 10 on the ordinate scale and $10^{8}$ cells $/ \mathrm{ml}$ or cells $/ \mathrm{ml}\left(10^{8}\right)$ as the label. No " $x$ " is used. This style is readily understandable because it is comparable to the use of $\mathrm{kg}$ or $\mathrm{mmol}$ on a coordinate.

As to a standard, it is unfortunate that the Council of Biological Editors did not deal with this question explicity. However, in the CBE Style Manual (Fifth edition, p. 79) they do set a style for units in tables, and it is this that has been adopted by the ASM for both graphs and tables.

In dealing with graphs, I suspect that the council could not agree among themselves. In the section of the manual dealing with illustrative material, 'Graphs' and 'Tables' are adjacent, and the latter includes this phrase, which in similar words can be traced back through earlier editions: "Except in rare instances, avoid numbers $\left(\times 10^{6}\right),\left(\times 10^{-6}\right)$ as multiplying factors in column headings; they have caused much confusion in biological literature

DonAld P. NiERLICH (Chairman, Nomenclature Committee Publications Board American Society for Microbiology) Department of Microbiology, College of Letters and Science,

University of California,

Los Angeles,

California 90024, USA

SIR-Luykx maintains that "quantity (unit $\times$ number)" is not incorrect. His defence of this form is based on viewing the bracketed expression simply as a descriptive label which he then interprets by identifying the unit-symbol with the numerical value of the quantity.

The point at issue is, however, not correctness versus incorrectness but rather clarity versus ambiguity. I and most of my colleagues use "quantity/(number $\times$ unit)" or "quantity/(prefixed-unit)" wherein the number or prefix may be a power of 10 . This accords with the Royal Society, (Quantities, Units and Symbols, 1971), with the policy of the Conference Générale des Poids et Mesures, and with the International Organization for Standardization with which, in turn, almost all national standardizing bodies cooperate. I find the carefully considered conclusions of these eminent bodies less ambiguous and generally more likeable than Luykx's arbitrary preferences. I observe that some "quantities" might cause me to replace our bracketed expression by a description such as "on the Beaufort scale".

EdWin Le Févre

7 Richmond Gardens,

London NW4 4RT, UK

SIR-Liébecq and Luykx have recently suggested how to label the axes of a graph. May I suggest another method?

To continue with the example introduced by Liébecq, if one wishes to show radioactivity data in the range of 5,000 c.p.m., surely one should label the axis, "Radioactivity $/ 10^{3}$ c.p.m.". with gradua- 